\title{
Effects of menarche,parity,primiparous age,and reproductive diseases on uterine fibroids of rural women in China
}

\section{Bing-Jie Wu}

Anhui Medical University https://orcid.org/0000-0003-1833-6007

\section{Chun-Yan Shao}

First Affiliated Hospital of Anhui Medical University

\section{Yun Zhu}

First Affiliated Hospital of Anhui Medical University

Kai Huang

Anhui Medical University

\section{Wu Wei}

First Affiliated Hospital of Anhui Medical University

\section{Xiu-Jun Zhang}

Anhui Medical University

Cheng-Yang Hu

Anhui Medical University

Fei Zhong ( $D$ 1845011420@stu.ahmu.edu.cn )

Anhui Medical University https://orcid.org/0000-0003-0263-7147

\section{Research article}

Keywords: Uterine fibroids, Menarche, Parity, Female reproductive health, Risk factors

Posted Date: November 15th, 2019

DOI: https://doi.org/10.21203/rs.2.17286/v1

License: (1) (1) This work is licensed under a Creative Commons Attribution 4.0 International License. Read Full License 


\section{Abstract}

Objectives With the increasing prevalence of hysteromyoma among Chinese rural women at childbearing age, it has become a priority to identify the risk factors that predispose to corporeity and promote early prevention. The aim of the study is to explore the relationship between menarche age, female reproductive health and uterine fibroids.

Methods Study participants included 2,200 rural women of reproductive age who were screened for a cross-sectional study in the Anhui province. Data collected by questionnaire survey, gynecological and laboratory examinations were analyzed by Univariate and multivariate analysis to evaluate the risk factors for uterine fibroids.

Results Of the 2,200 women, 440 had uterine fibroids. In general, women with endometriosis, ovarian cysts and early menarche were more likely to suffer from hysteromyoma. Factors including more parity, appropriate late primiparous age and normal menstrual cycle were protective of uterine fibroids.

Conclusions Our findings indicate that a variety of modifiable factors may increase the risk of uterine fibroids and that relevant health departments should develop effective prevention and intervention measures to improve the reproductive health of rural women.

\section{Introduction}

Uterine fibroids originate from muscle cells in the uterus, and are often initially diagnosed as small nodules and polyps. With fibroids growing, some of them can even swell the lower abdomen. Leiomyoma or uterine fibroid tumor, the most common female pelvic benign tumor is classified based on its location relative to the layers of the uterus (as subserous, intramural or submucosa), occurring with an estimated incidence of $20 \%-40 \%$ in women during their reproductive age ${ }^{1,2}$. Incidence of uterine leiomyoma varies with race and age ${ }^{3}$. Uterine leiomyoma is steroid dependent ${ }^{4}$. Because of the influence of estrogens and progestogens ${ }^{5}$, leiomyoma rarely occurs earlier than menarche and scarcely later than menopause. Women with uterine leiomyoma may have increased menstruation, prolonged menstruation, and lower abdominal pain during menstruation. However, the clinical manifestations of most patients are hidden or even no clinical manifestations ${ }^{6}$, which causes many women of childbearing age to miss the best treatment period, and most of them have to be treated by surgery. Most patients with late detection of uterine leiomyoma need to undergo hysterectomy, which is also the main reason why women are hospitalized for gynecological diseases ${ }^{7,8}$. Study has supported that the earlier girls with menarche, the more likely they are to have uterine fibroids ${ }^{9}$. Early age of menarche is also reported to be relevant to complications such as type 2 diabetes, angiocardiopathy, metabolic diseases ${ }^{10,11}$, and cancer ${ }^{12}$. The age of menarche can be influenced by genetic and environmental factors during childhood ${ }^{13}$, thereby supporting the "developmental origins of health and disease" hypothesis. 
Exploring the relationship between age of menarche, parity, female reproductive diseases and hysteromyoma is of remarkable clinical and public health importance, especially in the context of declining age of menarche and increasing prevalence of hysteromyoma. This study is a population-based study of rural women of reproductive age in Anhui province.

\section{Material And Methods \\ Setting and sample}

This large cohort cross-sectional study was conducted between August 2005 and November 2007 in Anhui province, which is located in the east-central part of china covering an area of $39600 \mathrm{~km}^{\wedge} 2$ and with a population of more than 70 million. At that time, more than $50 \%$ of the population lived in rural areas of the province; 17 million women were at child-bearing age, and nearly $80 \%$ of them were married.

This survey was designed by the Population and Family Planning Commission of Anhui Province and performed by Department of Public Health of Anhui Medical University. All workers gave informed consent and the study was approved by the Anhui Science and Technology Department and the Research Ethics Committee of Anhui Medical University. The selection of participants was carried out by a multistage stratification process as described previously.

Firstly, Anhui province was stratified based on administrative region and diverse landforms. Subsequently, several towns were picked out randomly within the stratification. Secondly in marking the town family planning service stations as the center, administrative villages randomly were selected within a $5 \mathrm{~km}$ radius from the center. Finally, qualified women from these administrative villages were investigated and women who could not recall with certainty their age at first menstruation were excluded to minimize bias in the outcome. A total of 53652 women were interviewed, of which 52874 responded to the questionnaires. Due to the large size of the original database, 2,200 women of reproductive age were randomly separated from the database after deleting the samples that were not consistent with the research topic.

\section{Questionnaire, disease diagnosis, and date collection and classification}

Questionnaires were handed to the interviewees by the staff to obtain specific study related information, which principally included sociodemographic characteristics, menstrual history, obstetrical history, health history, health care seeking behavior and so on. Prior to the start of the study, investigators were given permission to visit participants' home and maintain record of their home address to ensure high quality accuracy and completeness of the database. Information of women who arrived at the family planning service outlet of the villages was recorded. Residents who failed to show up were visited by investigators. Detailed information on the questionnaire survey is available in our previous articles ${ }^{14}$. 
Gynecologists, laboratory technicians, and health workers obtain female reproductive health status through gynecological examination, laboratory testing. Initially, subjects were interviewed to gather information regarding past gynecological history, abnormal symptoms in pudendum, discomfort or pain in hypogastrium or other signs. After that vaginal excretion or cervical sample were taken with vaginal speculum, and blood samples were collected separately from each participant in a disinfected room for the diagnosis of RTIs (Reproductive Tract Infection). Gynecologists used ultrasound scanners to diagnose uterine fibroids in the participants.

Considering that most interviewees were born before the 1990s, the weak economy and the availability of fewer material resources in rural Anhui, we divided menarche into 3 groups based on age of onset: $\leq 12$, 13 16(Ref. group), $\geq 17$ years. Primiparous agewas also divided into three groups: $\leq 20,21 \sim 25$ (Ref. group), $\geq 26$ years. The same grouping is done in parity: $0 \sim 1,2 \sim 3$ (Ref. group), $\geq 4$ children. According to the severity of symptoms, dysmenorrhea was divided into three groups: no (Ref. group), mild, and severe. Most of the remaining dichotomous data were naturally divided into two groups: non-exposed group (no $=0$ ) and exposed group (yes $=1$ ).

\section{Statistical analysis}

Two students utilized EpiData3.1 [EpiData Foreningen (EpiData Association), Odense, Denmark] to enter data and SPSS23.0 to analyze data separately. Univariate analysis was applied to calculate the odds ratio (OR) and $95 \%$ confidence interval $(95 \% \mathrm{Cl})$ to evaluate the relationship between diverse variables and incidence of uterine fibrosis. A multivariate stepwise logistic regression analysis was used to assess the net association between factors (including demographic characteristics, physiological characteristics, reproductive diseases) and hysteromyoma.

To minimize the effect of interference, dependent variables were controlled, as much as possible, in each multivariate stepwise logistic regression analysis. A value of $p<0.05$ and $95 \% \mathrm{Cl}$ of $\mathrm{OR}$ that did not span zero was considered statistically significant.

\section{Results}

\section{Various characteristics}

Of the 2,200 women, 440 had uterine fibroids. The incidence of uterine fibroids was $20 \%$. The sociodemographic characteristics, female physiology characteristic, and reproductive diseases are shown in Table 1-3. The average age of the 2,200 rural women of child-bearing age was $39.54 \pm 5.96$ years. Of the four age groups, the third group (36 45 years old) had the highest proportion (64.7\%) of women. 99.5\% of them were from Han nationality, and the rest were of ethnic minorities. 1,569 (73.1\%) were below the primary school level in 
education. Nearly half of them (45.5\%) never attended school (not been listed). Most people have stable marriages (97.5\%), the rest $2.5 \%$ including divorce, widowhood, remarriage, and so on. 54\% of them earned less than 10000 RMB.

About two-thirds (70.4\%) of women have their menarche at the age of 13 16, 11\% before 12 years old. 1855(84.3\%) of them had $2 \sim 3$ children. 847 women had a history of abortion or induced labor. 1472(66.9\%) people had their first child at the age of 21 25, 415(18.9\%) before 20 .

$731(33.2 \%)$ women had vaginitis, $11.4 \%$ with pelvic inflammatory disease, and $41 \%$ with dysmenorrhea. More details about the various characteristics of women were presented in Table 1 3.

\section{The distribution of uterine fibroids among diverse variables}

Based on demographics, there was no statistical difference in the frequency distribution of uterine leiomyoma in groupings based on nationality, occupation and yearly family income, but statistical differences were found in the distribution based on women's age, education and marital status $(\mathrm{p}<0.05)$. Based on physiological characteristics, there was no statistical difference in the frequency distribution of uterine leiomyoma based on the history of abortion, but significant differences were found in the distribution based on menarche, parity and primiparous age $(\mathrm{p}<0.001)$. With regard to female reproductive diseases, there were significant differences found in the distribution of uterine leiomyoma based on a history of vaginitis, pelvic inflammation, endometriosis, ovarian cyst and menstrual disorders ( $p<0.001$ ), only except the dysmenorrhea. More information was provided in table 1(Table1 is larger than A4 paper and is placed at the end of the text, before References).

\section{Risk factors for uterine fibroids}

Binary logistics regression analysis with the dependent variable of women with or without fibroids (no=0, Yes $=1$ ) and independent variables of various characteristics presented that most demographics (nationality, occupation, education, marital status, family income), 
except the women's age, were not associated with uterine leiomyomas (Table2). Compared to the second age group (26 34 years old), advanced age (age $\geq 35$ years old) was associated with an increased risk of leiomyomas.

Table2: Risk factors for uterine fibroids in sociological characteristics

$$
\text { Uterine fibroids }
$$

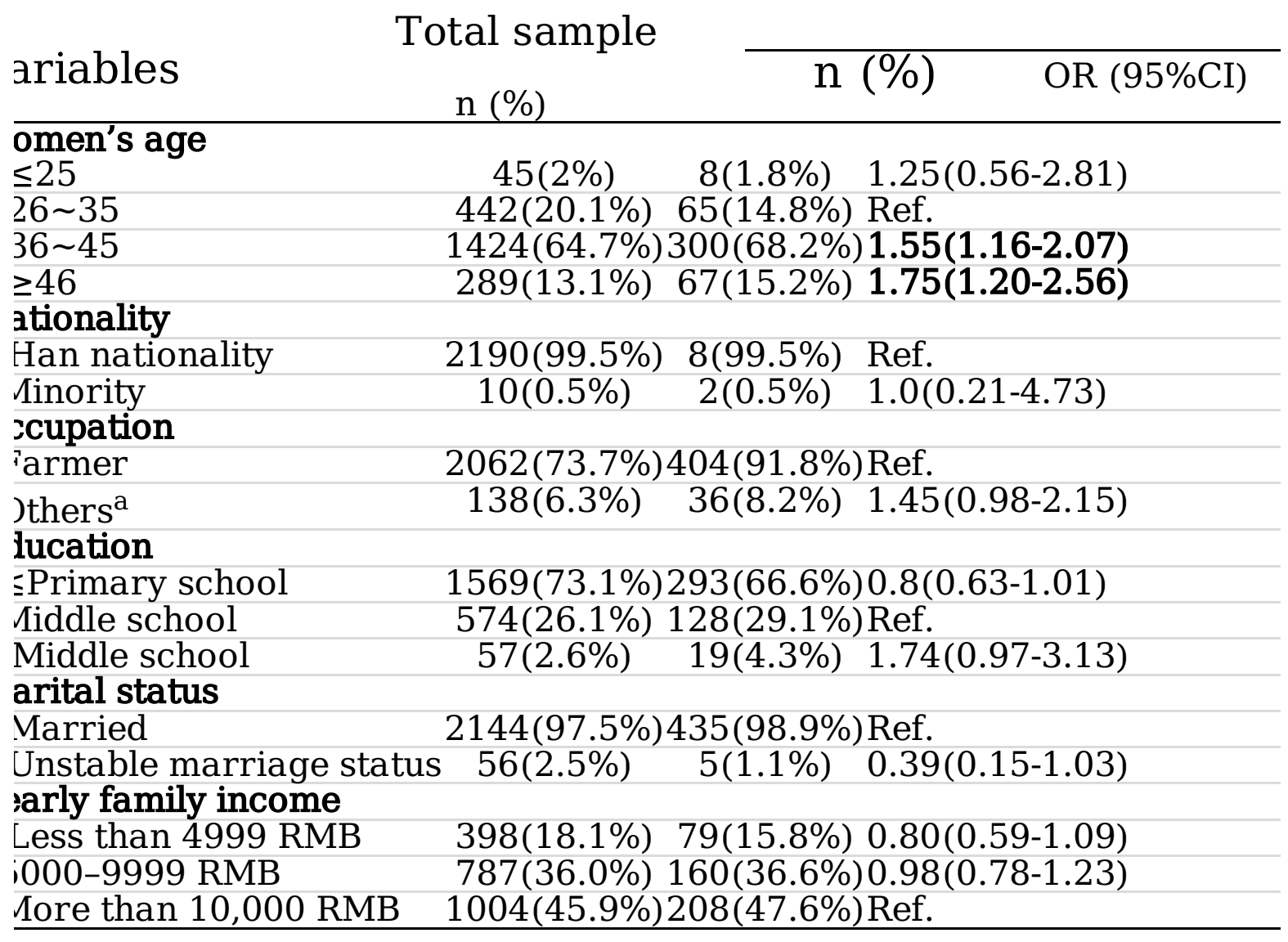

OR: odds ratio; CI: confidence interval.

Values $(\mathrm{P}<0.05)$ in bold mean they are statistically significant.

ancluding workers, businessmen, and waitress and so on.

Results in table3 suggested that AOM, parity, and primiparous age were significantly associated with uterine fibroids. People with early menarche $(\leq 12, \mathrm{OR}=1.57,1.16-2.12)$ or 
early primiparous age $(\leq 20, \mathrm{OR}=1.3,1.01-1.68)$ or less parity $(0 \sim 1$ child, $\mathrm{OR}=1.577,1.05$ 2.37) may have a higher risk of leiomyomas. However, abortion or induced labor (95\%CI: 0.78-1.20), pelvic inflammation (95\%CI:0.79-1.51), and dysmenorrhea (no, Ref.; mild, 95\%CI: 0.77-1.21; severe, 95\%CI: 0.83-1.84) were not materially associated with the risk of uterine fibroids. The rest results of gynecological diseases detailed in table3 also shown that the factors independently associated with an increased risk of leiomyomas were vaginitis $(O R=4.05,3.26-5.04)$, endometriosis $(O R=20.3,7.70-53.5)$, ovarian cyst $(\mathrm{OR}=8.84,4.72-16.53)$, and menstrual disorder $(\mathrm{OR}=9.17,4.59-18.33)$. Detailed information from the data was given in table3.

Table3. Risk factors for uterine fibroids in female physiology characteristic and reproductive diseases. 
Uterine fibroid

Total sample

Variables n (\%)

\begin{tabular}{|c|c|c|c|}
\hline \multicolumn{4}{|l|}{ Age of menarche } \\
\hline$\leq 12$ & $243(11 \%)$ & $71(16.1 \%)$ & $1.57(1.16-2.12)$ \\
\hline $13 \sim 16$ & 1549( & & Po \\
\hline$\geq 17$ & $408(18.5 \%)$ & $46(10.5 \%)$ & $0.48(0.35-0.67)$ \\
\hline Parity & & & \\
\hline $0 \sim 1$ & $122(5.5 \%)$ & $35(8 \%)$ & $1.577(1.05-2.37)$ \\
\hline $2 \sim 3$ & $1855(84.3 \%)$ & $377(85.7 \%)$ & Ref. \\
\hline$\geq 4$ & $223(10.2 \%)$ & $28(6.3 \%)$ & $0.56(0.37-0.85)$ \\
\hline Abortion or induced labor & & & \\
\hline No & $1353(61.5 \% \%)$ & $268(60.9 \%)$ & $0.97(0.78-1.20)$ \\
\hline Yes & $847(38.5 \%)$ & $172(39.1)$ & Ref. \\
\hline Primiparous age & & & \\
\hline$\leq 20$ & $415(18.9 \%)$ & $102(23.2 \%)$ & $1.3(1.01-1.68)$ \\
\hline $\begin{array}{l}21 \sim 25 \\
>26\end{array}$ & 147: & & \\
\hline$\geq 26$ & $313(14.2 \%)$ & $43(9.8 \%)$ & $0.64(0.45-0.89)$ \\
\hline Vaginitis & & & \\
\hline No & $1469(66.8 \%)$ & $178(40.5 \%)$ & \\
\hline Yes & 731(33.2\%) & $262(59.5 \%)$ & $4.05(3.26-5.04)$ \\
\hline Pelvic inflammation & & & \\
\hline No & 1949(88.6\%) & $386(87.9 \%)$ & Ref. \\
\hline $\begin{array}{l}\text { Yes } \\
\text { Endometriosis }\end{array}$ & $250(11.4 \%)$ & $53(12.1 \%)$ & $1.089(0.79-1.51)$ \\
\hline $\begin{array}{l}\text { Endometriosis } \\
\text { No }\end{array}$ & $21+2>+2$ & & \\
\hline Yes. & $29(1.3 \%)$ & $24(5.5 \%)$ & $20.3(7.70-53.5)$ \\
\hline Ovarian cyst & & & \\
\hline No & 2153(97.9\%) & $408(92.9 \%)$ & \\
\hline $\begin{array}{l}\text { Yes } \\
\text { Menstrual disorder }\end{array}$ & $46(2.1 \%)$ & $31(7.1 \%)$ & $8.84(4.72-16.53)$ \\
\hline $\begin{array}{l}\text { Menstrual disorder } \\
\text { No }\end{array}$ & & & \\
\hline $\begin{array}{l}\text { No } \\
\text { Yes }\end{array}$ & $\begin{array}{l}2161(98.3 \%) \\
38(1.7 \%)\end{array}$ & $\begin{array}{l}413(94.1 \%) \\
26(5.9 \%)\end{array}$ & $\begin{array}{l}\text { Ref. } \\
\text { 9.17(4.59-33) }\end{array}$ \\
\hline Dysmenorrhea & & & \\
\hline No & $1300(59.0 \%)$ & $259(58.8 \%)$ & \\
\hline Mild & & 14 & \\
\hline & $153(7.0 \%)$ & $36(8.2 \%)$ & $1.24(0.83-1.84)$ \\
\hline
\end{tabular}

OR: odds ratio; CI: confidence interval.

Values $(\mathrm{P}<0.05)$ in bold mean they are statistically significant.

\section{Discussion}

Considering the basic national conditions, rural areas are poorer, less informed and have less access to family planning services than cities, as a result, rural women are at a higher risk of gynecological diseases. Although the fertility rate of rural women in Anhui province is high, prevention of gynecological diseases is still insufficient. 
The influence of uterine fibroids on the female population is of great significance no matter from the social, economic or medical point of view. Fibroids in different locations of the uterus with different incidence, generally speaking, intramural fibroids are the most common, followed by sub-serosal fibroids, and finally sub-mucosal. The degree of their damage to fertility also depended on their locations, inversely, among which sub-mucosal fibroids are the most harmful to fertility ${ }^{15}$. Related research have confirmed that sub-mucosal fibroids have the lowest incidence, located beneath the endometrium, which more likely lead to irregular bleeding and adverse reproductive effects in women ${ }^{16,17}$ and prior studies have illustrated that infertility is also associated with uterine fibroids ${ }^{9,18}$, especially at earlier ages ${ }^{19}$. Although women with uterine fibroids often have irregular uterine bleeding ${ }^{20}$, the specific cause has not been identified. Hypothesis thought it may be caused by uterine fibroids pressing on the endometrial venous plexus. Our result, $20 \%$ prevalence rate in 2200 cases, is in line with available data ${ }^{1,2}$ which confirmed that fibroids are the most common pelvic tumor with an estimated incidence of $20 \%-40 \%$ in women during their child-bearing age. The prevalence of uterine fibroids is also age dependent. For example, in Germany prevalence of uterine fibroids increased from $21.3 \%$ (30-35 years old) to $62.8 \%$ (46-50 years old) and subsequently declined from $56.1 \%$ to $29.4 \%$ in women between 51 and over 55 years of age ${ }^{21}$. In fact, it is equivalent to the effect of estrogen because the secretion of estrogen varies in different age groups. Our research indicated that highest prevalence (68.2\%) of fibroids groups was found among people aged $36 \sim 45$ years ( $\mathrm{OR}=1.55,95 \% \mathrm{Cl}$ : $1.06-2.07)$, lower prevalence $(16.6 \%)$ among people aged $<35$ years, and the least morbidity $(15.2 \%)$ among women aged $\geq 46$ years. The highest prevalence appeared in age groups of 36 45 years were in agreement with previous study conducted elsewhere ${ }^{22}$, which also illustrated that uterine fibroid is very common among women in their $30 \mathrm{~s}$ to $40 \mathrm{~s}$ and age is a risk factor for uterine fibroids ${ }^{22,23}$. Uterine fibroids are estrogen-dependent, so decreased hormone levels in menopausal women may also explain the least prevalence (15.2\%) of fibroids age group ( $\geq 46$ years old).

From a genetic point of view, some studies have suggested an association between the age of menarche and chromosomes 6 and $9^{24}$. For a long time, genetic underpinnings of uterine fibroids were largely ignored by the scientific community. However, recent reports have proved that cytogenetics play an important role in the pathogenesis of fibroids. The TC227 allele of HMGA2 was shown to be involved in the regulation of tumor tumorigenesis and development ${ }^{25}$. A study on the histone analysis of fibroids demonstrated that overexpression of extracellular matrix, and estrogen and progesterone receptors are related to signal transduction pathways in the pathophysiology of fibroids ${ }^{26}$. Physiologically, menstruation is the periodic shedding of the endometrium influenced by various hormones; factors affecting the secretion of related hormones affect menstruation. Early menarche occurs due to higher estrogen levels ${ }^{27}$. In another word, early age of menarche is equivalent to early start of ovulation, and early exposure to estrogen and progesterone ${ }^{28}$, which could explain our results that early menarche age ( $\leq 12$ years, $\mathrm{OR}=1.57,95 \% \mathrm{Cl}: 1.16-2.12)$ is an adverse factor for fibroids. In summary, our study is quite consistent with previous reports on the relationship between the age of menarche and the prevalence of 
uterine fibroids ${ }^{9,29}$. These reports collectively indicated that the earlier the age of menarche, the higher the rate of fibroids ${ }^{29}$.

Agreed with prior studies, just as shown in table3, the number of births is a protective factor for uterine fibroids. With the decrease in parity $(0 \sim 1$ child, $O R=1.577,95 \% \mathrm{Cl}: 1.05-2.37)$, the prevalence of uterine fibroids is increasing ${ }^{19,30}$. One hypothesis suggests that the protective effect of pregnancy on fibroids occurs during postpartum uterine involution, which is actually more like uterine remodeling. The process includes high levels of apoptosis and contraction of muscle cells for regaining uterine size. Uterine remodeling can enhance the selective elimination of abnormal cells that have transformed during apoptosis. In other words, postpartum uterine regurgitation can eliminate abnormal tumor cells ${ }^{31}$. Another reason being temporary cessation of menstruation during pregnancy leads to less exposure to estrogen and progesterone.

As ovarian cancer and endometriosis share common genetic alterations, such as PTEN, p53, and bcl gene mutations, it is naturally inferred that malignant gene transition exists between them ${ }^{32}$. Women with symptomatic leiomyoma have a higher risk of endometriosis ${ }^{33}$, nevertheless, our results suggested that endometriosis is a risk factor( $\mathrm{OR}=20.3,95 \% \mathrm{Cl}$ : 7.7-53.5) for uterine fibroids, which reflected mutual causality.

Earlier study has observed women with incident fibroids, those with a previous BV diagnosis are more likely to have 2 or more fibroids compared with 1 fibroid $^{34}$. This is consistent with our study that found a positive association between vaginitis $(\mathrm{OR}=4.05,95 \% \mathrm{Cl}: 3.26-5.04)$ and the risk of developing uterine leiomyomas.

The symptoms of genital tract infection are usually ignored by women as they are not obvious, but longterm infection can stimulate bulking of the endometrium resulting in uterine fibroids ${ }^{35}$, which can has a capacity for increasing the risk of uterine fibroids ${ }^{36}$.

Early primiparous age $(\leq 20, \mathrm{OR}=1.3,95 \% \mathrm{Cl}: 1.01-1.68)$ has been associated with a significant increase the prevalence of uterine fibroids from table 3 . According to the information from encyclopedia of Chinese women, medicine health care voucher: people's endocrine systems will mature around the age of 23 , when their ovaries can release the highest quality ootid and the optimal reproductive age for women is 24 29 years old; Physiologically, due to the immaturity of the multiple systems in body,too early primiparous age will increase the risk of gynecological diseases and cervical cancer in the future. Therefore, we think our result is in line with clinical significance.

Shown in our study, both ovarian cysts $(\mathrm{OR}=8.84,95 \% \mathrm{Cl}: 4.72-16.53)$ and menstrual disorders $(\mathrm{OR}=$ 9.17, 95\% Cl: 4.59-18.33) have adverse effects on the prevalence of uterine fibroids. The ovary is a gonad organ whose main function is to produce ootid and secrete various gonadal hormone. Ovarian cysts will give rise to abnormal secretion of the hormone that can induce uterine fibroids. Noriko Kato and Tadashi Hayasaka identified ovarian tumors with functioning stroma is positively correlated with the increase of 
serum estrogen level ${ }^{37}$. The reasons for irregular menstruation vary and can arise due to diverse conditions ranging from hormone disorder, malignant tumor, reproductive tract infection, to the use of certain medications and so on. Furthermore, Jiao Jiao and Matthew Sagnelli have ascertained that an array of abnormally expressed genes present in patients with menstrual disorders also appeared in the signaling pathways of oncogenesis ${ }^{38}$.

\section{Conclusion}

In brief, our data indicates that female reproductive diseases and earlier menarche are risk factors for uterine fibroids, while multiple parity provides protection from uterine fibroids. Therefore, in order to reduce the prevalence of female uterine fibroids and improve the reproductive health index, it is necessary to prevent the above risk factors in advance.

\section{Limitations}

List of risk factors known to increase the occurrence of uterine fibroids have been listed in numerous articles, which are more comprehensive compared to our study results. This is mainly because the applicable sample size provided in our paper is small after deleting incomplete or inconsistent data. In addition, due to limited financial and human resources, we did not make a detailed classification of uterine fibroids and counted the number of uterine fibroids per patient. Differences in the clinical experience of ultrasound technicians may have prevented some women whose intrauterine fibroids are small from being detected.

\section{Declarations}

\section{Conflict of interest}

All authors declare no conflict of interest.

\section{Authors' contributions}

Author Bing-Jie Wu designed the study, performed the statistical analysis, wrote the protocol and the first draft of the manuscript. Bing-Jie Wu, Fei Zhong, Xiu-Jun Zhang and Cheng-Yang Hu helped to design the work and interpreted data, revised the contents of the manuscript which were inappropriately expressed. Chun-Yan Shao, Yun Zhu, Kai Huang and Wu Wei all participated in the data collation. All authors read approved the final version of the article.

\section{Acknowledgments}


The authors are very grateful for the help provided by the Reproductive Health Working Group, and the participants in the successful and smooth running of the study. In particular, participants' willingness to provide useful information at different times during the visit.

\section{Ethical compliance}

All the research procedures referring to interviewees which were scrupulously designed and implemented in the study conformed to moral standards of the Anhui Science and Technology Department and the Research Ethics Committee of Anhui Medical University in June 2006 (\#060230060).

\section{Informed consent}

Every participant involved in the research gave informed consent.

\section{Funding}

This study was supported by Scientific Research Fund for Candidates of Provincial Academic and Technical Leaders in 2018 (2018H175) and Anhui Provincial Natural Science Foundation (1208085MH143).

\section{Availability of data and material}

The corresponding author can provide the applicable data or material if the article requires.

\section{Author details}

${ }^{1}$ Department of Oncology, Fuyang Hospital of Anhui Medical University, Fuyang, Anhui, P. R. China. ${ }^{2}$ Department of Oncology $\mathbb{X}$ The First Affiliated Hospital of Anhui Medical University, Hefei, Anhui, P. R. China ${ }^{3}$ Department of Epidemiology and Biostatistics, School of Public Health, Anhui Medical University, 81\# Meishan Road, Hefei 230032, Anhui, People's Republic of China. ${ }^{4}$ Department of Humanistic Medicine, School of Humanistic Medicine, Anhui Medical University, 81\# Meishan Rode, Hefei, 230032, China

\section{Table}

Table1: Multiple characteristics of 2,200 women and the distribution of uterine fibroids among variables 


\begin{tabular}{|c|c|c|c|c|}
\hline Variables & $\begin{array}{l}\text { Women without } \\
\text { uterine fibroids } \\
\mathrm{n}(\%)\end{array}$ & $\begin{array}{c}\begin{array}{l}\text { Women with uterine } \\
\text { fibroids }\end{array} \\
\mathrm{n}(\%)\end{array}$ & & P-value \\
\hline $\begin{array}{l}\text { Women's age } \\
\leq 25 \\
26 \sim 35 \\
36 \sim 45 \\
\geq 46\end{array}$ & $\begin{array}{c}37(82.2 \%) \\
377(85.3 \%) \\
1124(78.9 \%) \\
222(76.8 \%)\end{array}$ & $\begin{array}{c}8(17.8 \%) \\
65(14.7 \%) \\
300(21.1 \%) \\
67(23.2 \%)\end{array}$ & 10.73 & $0.013<0.5$ \\
\hline Nationality & & & 0.000 & $=1.0$ \\
\hline Han nationality & $1752(80.0 \%)$ & $438(20.0 \%)$ & & \\
\hline Minority & $8(80.0 \%)$ & $2(20.0 \%)$ & & \\
\hline $\begin{array}{l}\text { Occupation } \\
\text { Farmer }\end{array}$ & 1658 (80.4\%) & 404 (19.6\%) & 3.410 & 0.065 \\
\hline Others $^{a}$ & $102(73.9 \% \%)$ & $36(26.1 \% \%)$ & & \\
\hline Education & & & 9.954 & $0.007<0.05$ \\
\hline$\leq$ Primary school & $1276(81.3 \%)$ & 293(18.7\%) & & \\
\hline Middle school & $446(77.7 \%)$ & $128(22.3 \%)$ & & \\
\hline घMiddle school & $38(66.7 \%)$ & $19(33.3 \%)$ & & \\
\hline $\begin{array}{l}\text { Marital status } \\
\text { Married }\end{array}$ & 1702 (79.7\%) & 432 (20.3\%) & 4.402 & $0.036<0.05$ \\
\hline $\begin{array}{l}\text { Unstable } \\
\text { marriage status }\end{array}$ & $51 \square 91.1 \% \square$ & $5 \square 8.9 \% \square$ & & \\
\hline $\begin{array}{l}\text { Yearly family income } \\
\text { Less than } 4999 \\
\text { RMB }\end{array}$ & 329 (82.7\%) & $69(17.3 \%)$ & 2.142 & 0.343 \\
\hline 5000-9999 RMB & $627(79.7 \%)$ & $160(20.3 \%)$ & & \\
\hline $\begin{array}{l}\text { More than 10,000 } \\
\text { RMB }\end{array}$ & $796(79.3 \%)$ & $208(20.7 \%)$ & & \\
\hline $\begin{array}{l}\text { Age of menarche } \\
\quad \leq 12\end{array}$ & $172(70.8 \%)$ & $71(29.2 \%)$ & 33.02 & $<0.001$ \\
\hline $13 \sim 16$ & $1226(79.1 \%)$ & $323(20.9 \%)$ & & \\
\hline$\geq 17$ & $362(88.7 \%)$ & $46(11.3 \%)$ & & \\
\hline Parity ${ }^{b}$ & & & 13.60 & 0.001 \\
\hline $0 \sim 1$ & $87(71.3 \%)$ & $35(28.7 \%)$ & & \\
\hline $2 \sim 3$ & 1478(79.7\%) & $377(20.3 \%)$ & & \\
\hline$\geq 4$ & $195(87.4 \%)$ & $28(12.6 \%)$ & & \\
\hline $\begin{array}{l}\text { Abortion or induced } \\
\text { labor } b\end{array}$ & $675(79.7 \%)$ & $172(20.3 \%)$ & 0.081 & 0.776 \\
\hline $\begin{array}{l}\text { Primiparous age }{ }^{\mathrm{b}} \\
\leq 20\end{array}$ & $313(75.4 \%)$ & $102(24.6 \%)$ & 13.11 & 0.001 \\
\hline $21 \sim 25$ & $1177(80 \%)$ & $295(20 \%)$ & & \\
\hline$\geq 26$ & $270(86.3 \%)$ & $43(13.7 \%)$ & & \\
\hline Vaginitis $^{c}$ & $469(64.2 \%)$ & $262(35.8 \%)$ & 171.7 & $<0.001$ \\
\hline Pelvic inflammation ${ }^{\mathrm{c}}$ & 197(85.7\%) & $33(14.3 \%)$ & 5.07 & $0.024<0.05$ \\
\hline
\end{tabular}




\begin{tabular}{|c|c|c|c|c|}
\hline Endometriosis ${ }^{c}$ & $5(17.2 \%)$ & $24(82.8 \%)$ & 72.53 & $<0.001$ \\
\hline Ovarian cyst ${ }^{c}$ & $15(32.6 \%)$ & $31(67.4 \%)$ & 66.14 & $<0.001$ \\
\hline Menstrual disorder ${ }^{c}$ & $12(31.6 \%)$ & $26(68.4 \%)$ & 56.83 & $<0.001$ \\
\hline Dysmenorrhea c & & & 1.358 & 0.507 \\
\hline No & $1041(80.1 \%)$ & $259(19.9 \%)$ & & \\
\hline Mild & $602(80.6 \%)$ & $145(19.4 \%)$ & & \\
\hline Severe & $117(80 \%)$ & $36(23.5 \%)$ & & \\
\hline
\end{tabular}

Values $(\mathrm{P}<0.05)$ in bold mean they are statistically significant.

${ }^{a}$ Including workers, businessmen, and waitress and so on.

${ }^{\mathrm{b}}$ Belong to female physiology characteristic

${ }^{\mathrm{c}}$ Female reproductive diseases

\section{References}

1.Hatasaka H. The evaluation of abnormal uterine bleeding. Clin Obstet Gynecol 2005;48:258-73.

2.Goodwin SC, Spies JB, Worthington-Kirsch R, et al. Uterine artery embolization for treatment of leiomyomata: long-term outcomes from the FIBROID Registry. Obstet Gynecol 2008;111:22-33.

3.Marshall LM, Spiegelman D, Barbieri RL, et al. Variation in the incidence of uterine leiomyoma among premenopausal women by age and race. Obstet Gynecol 1997;90:967-73.

4.Kim JJ, Sefton EC. The role of progesterone signaling in the pathogenesis of uterine leiomyoma. Mol Cell Endocrinol 2012;358:223-31.

5.Rein MS, Barbieri RL, Friedman AJ. Progesterone: a critical role in the pathogenesis of uterine myomas. Am J Obstet Gynecol 1995;172:14-8.

6.Okolo S. Incidence, aetiology and epidemiology of uterine fibroids. Best Pract Res Clin Obstet Gynaecol 2008;22:571-88.

7.Levy B, Mukherjee T, Hirschhorn K. Molecular cytogenetic analysis of uterine leiomyoma and leiomyosarcoma by comparative genomic hybridization. Cancer Genet Cytogenet 2000;121:1-8.

8.Viswanathan M, Hartmann K, McKoy N, et al. Management of uterine fibroids: an update of the evidence. Evid Rep Technol Assess (Full Rep) 2007:1-122.

9.Marshall LM, Spiegelman D, Goldman MB, et al. A prospective study of reproductive factors and oral contraceptive use in relation to the risk of uterine leiomyomata. Fertil Steril 1998;70:432-9. 
10.Sachan B, Idris Z, Jain S, Kumri R, A. S. Age at menarche and menstrual problems among schoolgoing adolescent girls of a north Indian district.. Journal of Basic and Clinical Reproductive Sciences 2012;1:56-9.

11.Aryeetey R, Ashinyo A, Adjuik M. Age of menarche among basic level school girls in Medina, Accra. Afr J Reprod Health 2011;15:103-10.

12.Kadlubar FF, Berkowitz GS, Delongchamp RR, et al. The CYP3A4*1B variant is related to the onset of puberty, a known risk factor for the development of breast cancer. Cancer Epidemiol Biomarkers Prev 2003;12:327-31.

13.Choi JH, Yoo HW. Control of puberty: genetics, endocrinology, and environment. Curr Opin Endocrinol Diabetes Obes 2013;20:62-8.

14.Zhang XJ, Shen Q, Wang GY, et al. Risk factors for reproductive tract infections among married women in rural areas of Anhui Province, China. Eur J Obstet Gyn R B 2009;147:187-91.

15.Lisiecki M, Paszkowski M, Wozniak S. Fertility impairment associated with uterine fibroids - a review of literature. Prz Menopauzalny 2017;16:137-40.

16.Wegienka G, Baird DD, Hertz-Picciotto I, et al. Self-reported heavy bleeding associated with uterine leiomyomata. Obstet Gynecol 2003;101:431-7.

17.Lippman SA, Warner M, Samuels S, Olive D, Vercellini P, Eskenazi B. Uterine fibroids and gynecologic pain symptoms in a population-based study. Fertil Steril 2003;80:1488-94.

18.Ross RK, Pike MC, Vessey MP, Bull D, Yeates D, Casagrande JT. Risk factors for uterine fibroids: reduced risk associated with oral contraceptives. Br Med J (Clin Res Ed) 1986;293:359-62.

19.Faerstein E, Szklo M, Rosenshein N. Risk factors for uterine leiomyoma: a practice-based case-control study. I. African-American heritage, reproductive history, body size, and smoking. Am J Epidemiol 2001;153:1-10.

20.Ding CY, Wang J, Cao Y, et al. Heavy menstrual bleeding among women aged 18-50years living in Beijing, China: prevalence, risk factors, and impact on daily life. Bmc Womens Health 2019;19.

21.Ahrendt HJ, Tylkoski H, Rabe T, et al. Prevalence of uterine myomas in women in Germany: data of an epidemiological study. Arch Gynecol Obstet 2016;293:1243-53.

22.Zimmermann A, Bernuit D, Gerlinger C, Schaefers M, Geppert K. Prevalence, symptoms and management of uterine fibroids: an international internet-based survey of 21,746 women. Bmc Womens Health 2012;12:6. 
23.Schwartz SM, Marshall LM, Baird DD. Epidemiologic contributions to understanding the etiology of uterine leiomyomata. Environ Health Perspect 2000;108 Suppl 5:821-7.

24.Montgomery GW, Zondervan KT, Nyholt DR. The future for genetic studies in reproduction. Mol Hum Reprod 2014;20:1-14.

25. Hodge JC, Cuenco KT, Huyck KL, et al. Uterine leiomyomata and decreased height: a common HMGA2 predisposition allele. Hum Genet 2009;125:257-63.

26.Rizzello A, Franck J, Pellegrino M, et al. A Proteomic Analysis of Human Uterine Myoma. Curr Protein Pept Sci 2017;18:167-74.

27.MacMahon B, Trichopoulos D, Brown J, et al. Age at menarche, urine estrogens and breast cancer risk. International journal of cancer 1982;30:427-31.

28.Apter D, Vihko R. Early menarche, a risk factor for breast cancer, indicates early onset of ovulatory cycles. J Clin Endocrinol Metab 1983;57:82-6.

29.Edwards DRV, Baird DD, Hartmann KE. Association of Age at Menarche With Increasing Number of Fibroids in a Cohort of Women Who Underwent Standardized Ultrasound Assessment. Am J Epidemiol 2013;178:426-33.

30.Wise LA, Palmer JR, Harlow BL, et al. Reproductive factors, hormonal contraception, and risk of uterine leiomyomata in African-American women: a prospective study. Am J Epidemiol 2004;159:113-23.

31.Baird DD, Dunson DB. Why is parity protective for uterine fibroids? Epidemiology 2003;14:247-50.

32.Nezhat F, Datta MS, Hanson V, Pejovic T, Nezhat C, Nezhat C. The relationship of endometriosis and ovarian malignancy: a review. Fertil Steril 2008;90:1559-70.

33.Nezhat C, Li A, Abed S, et al. Strong Association Between Endometriosis and Symptomatic Leiomyomas. Jsls-J Soc Laparoend 2016;20.

34.Moore KR, Baird DD. Self-reported bacterial vaginosis and risk of ultrasound-diagnosed incident uterine fibroid cases in a prospective cohort study of young African American women. Ann Epidemiol 2017;27:749-51 e1.

35.Zhang L, Yu J-J. Logistic regression analysis of related risk factors of uterine fibroids. Journal of Southeast University(Medical Science Edition) 2012;31:213-6.

36.Guo L-X, Lu Z-L. Analysis of risk factors of uterine fibroids. Journal of Ningxia Medical University 2016;38:431-3.

37.Kato N, Hayasaka T, Takeda J, Osakabe M, Kurachi H. Ovarian tumors with functioning stroma: a clinicopathologic study with special reference to serum estrogen level, stromal morphology, and 
aromatase expression. Int J Gynecol Pathol 2013;32:556-61.

38.Jiao J, Sagnelli M, Shi B, et al. Genetic and epigenetic characteristics in ovarian tissues from polycystic ovary syndrome patients with irregular menstruation resemble those of ovarian cancer. Bmc Endocr Disord 2019;19. 